\title{
The Relationship between Composite Measures of Glycemic Control and Beta-Cell Function in Type 2 Diabetes
}

\author{
Klaus Dieter Kohnert ${ }^{1 *}$, Peter Heinke ${ }^{1}$, Lutz Vogt ${ }^{2}$, Petra Augstein ${ }^{1,3}$ and Eckhard Salzsieder ${ }^{1}$ \\ ${ }^{1}$ Institute of Diabetes Gerhardt Katsch Karlsburg, Germany \\ ${ }^{2}$ Diabetes Service Center, Germany \\ ${ }^{3}$ Department of Medicine A, University Medicine Greifswald, Germany
}

Submission: July 17, 2017; Published: August 30, 2017

*Corresponding author: Klaus Dieter Kohnert, Division of Clinical Research, Institute of Diabetes Gerhardt Katsch Karlsburg, Germany, Tel: + 49(0)383-556-8406; Email: kohnert@diabetes-karlsburg.de

\begin{abstract}
Objective: To investigate the relationships between indices of the quality of glycemic control and beta-cell function and insulin sensitivity, using composite metrics derived from continuous glucose monitoring data and measures of beta cell function obtained from liquid meal tolerance tests (LMTT).

Design and Methods: This is a retrospective, observational, cross-sectional study that included 56 noninsulin treated subjects with type 2 diabetes. We used continuous glucose monitoring and LMTT data after withdrawal of oral antidiabetic drugs for computation of the composite glycemic control metrics Q-score, ADRR, and GRADE. The LMTT-based disposition index calculated from the ratio of the area-under-the insulincurve to the area-under-the-glucose-curve provided the estimate of beta cell function in relation to the insulin sensitivity. The Matsuda index served as correlate for the whole-body insulin sensitivity.

Results: We demonstrated inverse, curvilinear relationships between the composite metrics of glucose control and beta cell function. The LMTT-DI was the main predictor variable of the Q-score, ADRR, and GRADE with diabetes duration as the minor one (Q-score: LMTT-DI, $\beta=-0.018$ $\pm 0.002, p<0.001$; diabetes duration, $\beta=0.267 \pm 0.082, p=0.002, R^{2}=0.598$ ), whereas the Matsuda insulin sensitivity index did not contribute in these multivariate regression models.

Conclusion: The strength of association between the investigated composite metrics of glucose control and the beta cell indices enables assessment of the beta cell reserve from continuous glucose monitoring data for optimization of glycemic control before therapy escalation is considered. Our results support the view that maintaining or restoring of beta cell function is pivotal to improve diabetes treatment. The use of composite metrics simplifies clinical judgment through stratification of the quality of glycemic control into Good, Satisfactory, Fair, and Poor.

Keywords: Q-score; ADRR; GRADE; Disposition index; Insulin secretion index; Matsuda insulin sensitivity index; Type 2 diabetes

Abbreviations: ADRR: Average Daily Risk Range; CGM: Continuous Glucose Monitoring; Gluc: Glucose; GRADE: Glycemic Risk Assessment Diabetes Equation; AUC: Total Area Under the Curve AUCins/gluc ; ISI : Insulin Secretion Index; Ins: Insulin; LMTT-DI: Liquid Meal Tolerance TestBased Disposition Index; \%GRADE ${ }_{\text {hyp }}$ and \%GRADE Insulin Secretion Index; LBGI: Low Blood Glucose Index; LMTT-DI: Liquid Meal Tolerance Test-based Disposition Index; Matsuda Index: Index of Insulin Resistance; Q-score: Quality Score Of Glycemic Control
\end{abstract}

\section{Introduction}

Since the more widely use of continuous glucose monitoring (CGM), researchers and clinicians became aware of insufficiencies in the use of HbA1c as the sole measure of the quality of glycemic control in diabetes. Percentile scores for hypo- and hyperglycemia or composite markers gained increasing attention in the management of the large amounts of data provided by CGM [1-3].
Proposed composite markers are, for example, ADRR [4], GRADE [5], the "glucose pentagon" [6], the hypoglycemia-A1c score [7] or the Q-score [8], combining information from the overall glycemic control, hypo- and hyperglycemia, and several types of glycemic variability. The recently introduced personal glycemic state (PGS) is a composite metric [9] similar to our Q-score. 


\section{Current Research in Diabetes \& Obesity Journal}

Such measures could help assess the efficacy of therapeutic interventions and individualize diabetes treatment. Although used in a few studies as glycemic outcomes measures [10-15] the application of composite metrics in research and clinical practice is as yet limited [16]. The implication of metabolic factors other than metrics of glycemia possibly reflected by or closely related to these measures could provide a better understanding and broaden their application. All the variables combined in the other composite measures are apparently more or less related to beta cell dysfunction and insulin resistance, even though, the degree of their association is not well known. We previously showed that in type 2 diabetes (T2D) glycemic variability is strictly related to postprandial beta cell function [17], and others demonstrated relationships between glycemic variability and functional variables in type 1 diabetes [18]. Thus, it is conceivable that these composite measures of the quality of short-term glycemic control may provide meaningful data for the assessment of the patients' beta cell functional reserve and insulin sensitivity. Whether the other quality metrics can complement or even replace measures of beta cell function and insulin action in detecting the progression of the disease process or the efficacy of the therapeutic intervention, has not been investigated. We hypothesize that the composite measures do not only reflect short-term changes in glycemia but underlying functional defects of the beta cell and insulin sensitivity during the worsening of diabetes control. Addressing this issue, we used composite markers of glycemic control derived from continuous glucose monitoring and the liquid meal tolerance test-based disposition index (LMTT-DI) for evaluation of beta cell function and the Matsuda index as the measure of insulin sensitivity.

\section{Subjects and Methods}

\section{Database}

The present investigation is cross-sectional and used anonymized data obtained from patients with type 2 diabetes (T2D). For data analysis, we applied validated measures of glycemic control derived from retrospective ambulatory continuous glucose monitoring (CGM) profiles (MiniMed Solution Software, Medtronic MiniMed) and used established indices of beta cell function derived from liquid meal tolerance tests. After a $12 \mathrm{~h}$ overnight fast, all patients had received a standardized 500 $\mathrm{mL}$ liquid meal consisting of $75 \mathrm{~g}$ carbohydrate, $58 \mathrm{~g}$ fat, and $30 \mathrm{~g}$ protein to total $1,000 \mathrm{kcal}$. The patients had CGMs performed with glucose sensors placed on their abdomen. Recordings with a mean duration of $60 \mathrm{~h}$ and a minimum of four glucose meter calibrations per day provided the data for the calculations. We followed the validity criteria given by the manufacturer $(\geq 3$ paired sensor/meter readings and mean absolute difference $\leq 28 \%$ ).

\section{Study subjects}

The Table 1 shows that the study cohort comprised 56 wellcontrolled patients with T2D who had received diet alone or oral antidiabetic drugs. Seventy-nine percent of the patients had taken blood pressure lowering medication. Since the original study [17] had received ethical approval and, before inclusion, all study participants provided their written informed consent, this retrospective data analysis required no further approval.

Table 1: Clinical and laboratory data. Data are mean \pm SD or median $\left(25^{\text {th }}-75^{\text {th }}\right.$ percentile).

\begin{tabular}{|c|c|}
\hline Number of Patients & 56 \\
\hline Age (years) & $64.4 \pm 8.6$ \\
\hline Sex men/women & $29 / 27$ \\
\hline Body mass index $\left(\mathrm{kg} / \mathrm{m}^{2}\right)$ & $29.9 \pm 3.7$ \\
\hline Waist circumference $(\mathrm{cm})$ & $102.8 \pm 12.6$ \\
\hline Diabetes heredity, No (\%) & $27(48.2)$ \\
\hline \multicolumn{2}{|c|}{ Blood pressure (mmHg) } \\
\hline Systolic & $135.0(130.0-150.0)$ \\
\hline Diastolic & $80.0(80.0-85.0)$ \\
\hline Known diabetes duration (years) & $5.5(2.0-10.0)$ \\
\hline \multicolumn{2}{|c|}{ Diabetes treatment, No (\%) } \\
\hline Diet alone & $23(41.1)$ \\
\hline Insulin sensitizer & $12(21.4)$ \\
\hline Insulin secretagogues & $13(23.2)$ \\
\hline $\begin{array}{l}\text { Insulin secretagogues combined } \\
\text { with sensitizers }\end{array}$ & $8(14.3)$ \\
\hline Hemoglobin A1c (\%) & $6.1(5.7-7.2)$ \\
\hline$(\mathrm{mmol} / \mathrm{mol})$ & $43(39-55)$ \\
\hline Fasting plasma glucose (mmol/L) & $7.7(6.5-9.1)$ \\
\hline Fasting insulin (pmol/L) & $99.6(71.80-128.10)$ \\
\hline Fasting C-peptide (nmol/L) & $0.88(0.71-1.26)$ \\
\hline Triglyceride (mmol/L) & $1.8(1.3-2.5)$ \\
\hline HDL cholesterol (mmol/L) & $1.3(1.1-1.5)$ \\
\hline
\end{tabular}

\section{Indices of quality of glycemic control}

These indices were the Low Blood Glucose Index (LBGI), High Blood Glucose Index (HBGI), average daily risk range (ADRR) [3], Glycemic Risk Assessment Diabetes Equation (GRADE), \% GRADE hypoglycemia, \% GRADE hyperglycemia [4], and the newly developed Q-score [8]. The Q-score integrates the variables mean glucose, glucose range, time in glycemia $\left(\mathrm{t}_{\mathrm{G}}\right)<3.9$ $\mathrm{mol} / \mathrm{L}$, and $>8.9 \mathrm{mmol} / \mathrm{L}$, and mean of daily differences (MODD). Factor analysis allowed the selection of these variables. To ensure equivalent weight the variables were standardized by z-transformation, and the Q-score was then computed according to the formula [8], as previously described:

$$
\begin{aligned}
& \text { Q-Score }=8+\frac{\text { mean glucose }-7.8}{1.7}+\frac{\text { range }-7.5}{2.9}+\frac{\mathrm{t}_{\mathrm{G}<3.9}-0.6}{1.2} \\
& \quad \frac{\mathrm{tG}>8.9-6.2}{5.7}+\frac{\mathrm{MODD}-1.8}{0.9}
\end{aligned}
$$

In this formula, hypoglycemia indicates time spent below the range $<3.9 \mathrm{mmol} / \mathrm{L}(\mathrm{tG}<3.9)$ and time spent above the target range $>8.9 \mathrm{mmol} / 1\left(\mathrm{t}_{\mathrm{G}}>8.9\right)$ is defined as hyperglycemic, 


\section{Current Research in Diabetes \& Obesity Journal}

respectively. Glycated hemoglobin (HbA1c) was determined by standard methods and used as glucose exposure measure.

\section{Indices of beta cell function and insulin sensitivity}

Before commencing the study procedure, blood glucose lowering medication was withdrawn and substituted with placebo for eight days. We used plasma glucose and insulin concentrations obtained during the liquid meal tolerance test (LMTT) to calculate indices of insulin secretion and insulin sensitivity $[19,20]$. We calculated the Insulin secretion index (total $\mathrm{AUC}_{\text {ins/gluc }}$ ) as total area under the curve for plasma insulin (pmol/L $\mathrm{x} 150 \mathrm{~min}$ ) from 0 to $150 \mathrm{~min}$ divided by the total area

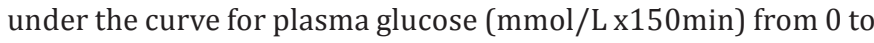
$150 \mathrm{~min}$. The areas under the curve (AUC) were calculated using the trapezoidal method. Fasting glucose $\left(\mathrm{Gluc}_{0}\right)$ and fasting insulin $\left(\mathrm{Ins}_{0}\right.$ ) and the respective LMTT mean post meal glucose mean glucose and mean insulin concentrations provided the data for computation of the Matsuda insulin sensitivity index (Matsuda index) according to the formula 10,000/sqrt (Gluc $\mathrm{x}$ Ins0 $\mathrm{x}$ mean glucose $\mathrm{x}$ mean insulin). Beta cell function taking the prevailing insulin sensitivity into account was assessed by Results

Table 2: Correlation matrix presented as spearman correlation coefficients $r$ for $\beta$-cell function and insulin resistance with quality indices of glucose control. Values significant at the $p<0.001$ level (two sided) are shown in bold font.

\begin{tabular}{|c|c|c|c|c|c|c|c|c|c|c|}
\hline & ISI & $\begin{array}{l}\text { Matsuda } \\
\text { index }\end{array}$ & LMTT-DI & Q-score & ADRR & LBGI & HBGI & GRADE & $\begin{array}{c}\text { GRADE } \\
\text { hypo }\end{array}$ & $\begin{array}{c}\text { \%GRADE } \\
\text { hyper }\end{array}$ \\
\hline ISI & 1 & & & & & & & & & \\
\hline Matsuda index & -0.355 & 1 & & & & & & & & \\
\hline LMTT-DI & 0.571 & -0.487 & 1 & & & & & & & \\
\hline Q-score & -0.484 & -0.383 & -0.789 & 1 & & & & & & \\
\hline ADRR & -0.474 & -0.396 & -0.810 & 0.949 & 1 & & & & & \\
\hline LBGI & 0.489 & 0.162 & -0.704 & -0.432 & -0.514 & 1 & & & & \\
\hline HBGI & -0.547 & -0.405 & -0.892 & 0.915 & 0.941 & -0.670 & 1 & & & \\
\hline GRADE & -0.558 & -0.397 & -0.896 & 0.905 & 0.926 & -0.690 & 0.99 & 1 & & \\
\hline$\% \mathrm{GRAD}_{\text {Ehypo }}$ & 0.304 & 0.09 & 0.44 & -0.13 & -0.23 & 0.715 & -0.407 & -0.407 & 1 & \\
\hline$\%$ GRADE $_{\text {hyper }}$ & -0.512 & -0.407 & -0.869 & 0.897 & 0.921 & -0.682 & 0.975 & 0.976 & -0.422 & 1 \\
\hline
\end{tabular}

Table 2 shows the degree of correlation between the scores of quality of glycemia and the indices of beta cell function. On Spearman's correlation analysis, the strength of associations of these scores with the LMTT-derived disposition index (LMTTDI) was high; moderate with the insulin secretion index (total $\mathrm{AUC}_{\text {ins/gluc }}$ ), and weak with the Matsuda insulin sensitivity index. Of note, we found a stronger correlation of LMTT-DI with the low blood glucose index LBGI than with the $\% \mathrm{GRADE}_{\text {hypoglycemia }}$ index.

The beta cell function indices, LMTT-DI and insulin secretion index were associated with the quality of glycemic control. Figure 1 demonstrates that LMTT-DI and insulin secretion index decreased with increasing Q-score categories and was lowest in the state of glycemia defined as poor. Even though the Matsuda insulin sensitivity index did significantly differ between good $(\leq 5.9)$ and satisfactory (6.0-8.4) glycemic control, it remained calculation of the liquid meal tolerance test-based disposition index (LMTT-DI) according to the formula: Matsuda index $\mathrm{x}$ total $\mathrm{AUC}_{\text {ins/gluc }}[20]$.

\section{Statistical analysis}

The variables are presented either as means \pm SD or as medians $\left(25^{\text {th }}-75^{\text {th }}\right.$ percentile $)$. Insulin is given as $\mathrm{pmol} / \mathrm{L}$ and glucose as mmol/L. For comparison of continuous variables, we used either one-way analysis of variance (ANOVA) or KruskalWallis one way analysis, as appropriate. Control of multiple pair wise comparisons was performed using the Holm-Sidak and Dunn's method, respectively. We used Spearman's correlation analysis, best subset regression with Mallow Cp statistic, and multivariate regression models to relate beta cell function and insulin sensitivity to indices of the quality of glycemic control. Potential confounding variables were age, sex, diabetes heredity, diabetes duration, and waist circumference. A variance inflation factor of and Durbin-Watson statistic served as the criterion for co- linearity. $\mathrm{P}<0.05$ was considered statistically significant. The statistical analysis used the Statistical Package for the Social Sciences software package (version 17.0; SPSS, Chicago, IL) rather unchanged in the higher Q-score categories. Figure 2 reveals that the relationship between the Q-score and beta cell function, as defined by the LMTT-DI, was inverse, nonlinear ( $\mathrm{r}$ $=0.873, \mathrm{p}<0.001)$. A decrease in LMTT-DI below $255\left(1 / \mathrm{mmol}^{2}\right)$ resulted in a steep increase in the Q-scorevalues. We also observed significant curvilinear associations of similar magnitude (not shown) between LMTT-DI and ADRR ( $\mathrm{r}=0.865, \mathrm{p}<0.001$ ) and GRADE ( $r=0.908, p<0.001$ ). To assess the independent effects of the LMTT-DI beta cell function and the Matsuda index on the quality of glycemic control, we chose the Q-score and applied the best subset regression analysis with Mallow Cp statistic, including possible confounders such as sex, age, diabetes heredity, diabetes duration, and waist circumference. The significant variables obtained from this analysis entered a multiple regression model, which verified the LMTT-DI and diabetes duration as predictor variables of the Q-score (LMTT- 
DI, $\beta=-0.018 \pm 0.002, p<0.001$; diabetes duration, $\beta=0.267 \pm$ $\left.0.082, p=0.002, R^{2}=0.598\right)$. A variance inflation factor of $\leq 1.10$ and a value of 1.79 in the Durbin-Watson test provided evidence for the absence of co- linearity. ADRR and GRADE, as dependent variables in this model, produced $R^{2}$ values of 0.572 and 0.682 , respectively, both $\mathrm{p}<0.001$. The Matsuda insulin sensitivity index did not significantly contribute.

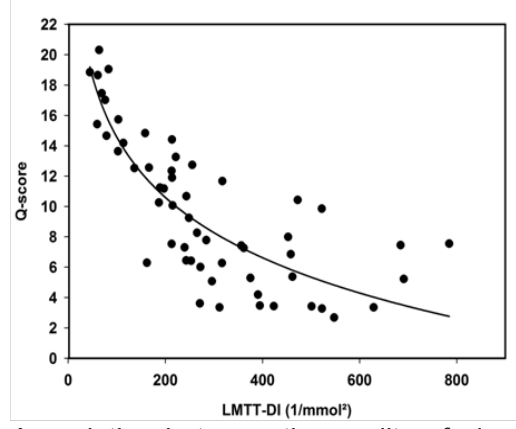

Figure 1: Association between the quality of glycemia based on Q-score categorization and beta-cell function measured by the disposition and insulin secretion index and the Matsuda index as the measure of insulin sensitivity in well-controlled patients with T2D $(n=56)$. Between-category differences were estimated by one-way analysis of variance and were statistically significant $(A: p<0.001, B: p<0.001$, and $C: p=0.027)$. Indicated differences were two-tailed test results. Q-score thresholds and the corresponding categories of glycemic control: $\leq 5.9$; Good, 6.0-8.4; Satisfactory, 8.5-11.9; Fair, and $\geq 12.0$; Poor.

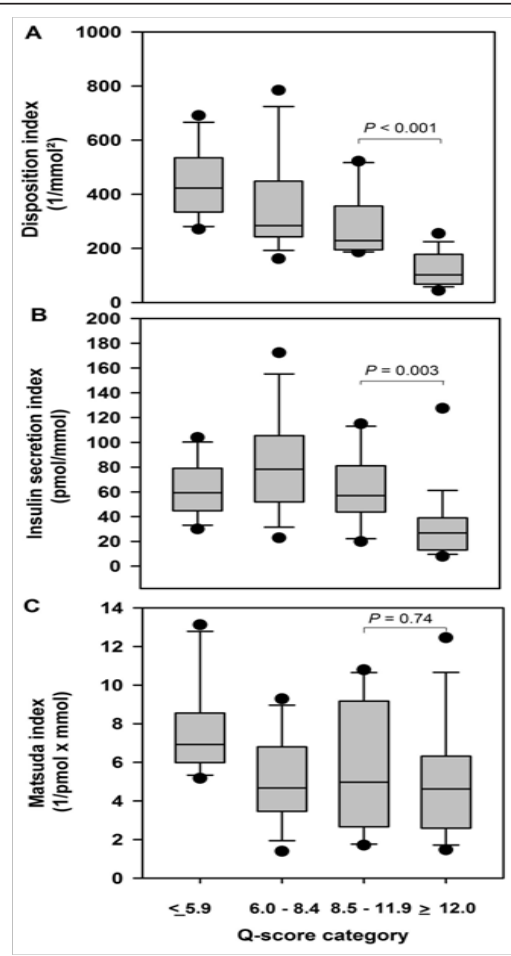

Figure 2: Relationship between the liquid meal tolerance testbased disposition index (LMTT-DI) and the quality of glycemic control as defined by the Q-score in well-controlled, noninsulin treated patients with T2D $(n=56)$. The regression line was obtained by the nonlinear regression equation: $\mathrm{Q}$-score $=-5.884$ In (LMTT-DI) + $41.844\left[R^{2}( \pm\right.$ SE $\left.)=0.762 \pm 2.336, p<0.001\right]$.
We have shown in this retrospective study that composite metrics of the quality of glycemic control such as the Q-score, ADRR, and GRADE depend primarily on the beta cell function, as indicated by the LMTT-derived disposition index. The curvilinear relationship between the LMTT-DI and the quality indices of glycemia implies that the better the beta cell reserve, the better the glucose control (lower quality indices). As exemplified by the Q-score, the beta cell functional capacity at < ②55 $\left(1 / \mathrm{mmol}^{2}\right)$ associated with a drastic increase toward poor glycemic control ( $Q$-score levels $\geq 12.0$ ). The disposition index LMTT-DI assesses the insulin secretion related to the wholebody insulin sensitivity and is an important, validated measure to quantify beta cell function [21]. It was an unexpected finding that the Matsuda insulin sensitivity index correlated weakly with the composite indices of the quality of glycemia and did not significantly contribute to their variance. Except for diabetes duration, the confounding factors sex, age, diabetes heredity, and waist circumference did not affect the quality indices of diabetes control. The beta cell function was the dominant predictor variable, explaining 52,48 , and $60 \%$ of the variance in the Q-score, ADRR, and GRADE, whereas the diabetes duration defined only 8-9\%. Park et al. [22] reported weaker correlations between ADRR and HOMA-\%B in patients with T2D than we found between ADRR and LMTT-DI in our diabetes cohort. The explanatory variables LMTT-DI and diabetes duration could not entirely elucidate the interindividual variability of the quality of glycemic control metrics. It appears that other factors such as carbohydrate consumption, treatment duration or modality of baseline antidiabetic therapy may partly be responsible for the residual variability. Since the study participants did not receive standardized diet, carbohydrate consumption was not accurately assessable. Although the immediate pharmacological effects of antidiabetic drugs were washed out, glucose toxic effects affecting the beta cell prevailed.

Limitations of the current investigation are the retrospective nature and the relatively small number of study participants. The strength is that we assessed the composite metrics of the quality of glycemia and the indices of beta cell function as well as insulin sensitivity during oral drug withdrawal to mostly eliminate therapeutic influences [17].

\section{Conclusion}

In summary, we demonstrate the existence of inverse, curvilinear relationships between composite metrics of glucose control and beta cell function. The strength of association between the investigated composite glucose control measures and the beta cell indices was comparable. The close relationships, described herein, enable assessment of the beta cell reserve for optimization of glycemia before therapy escalation is considered. Furthermore, our results support the view that maintaining or restoring of beta cell function is pivotal to improve the quality of diabetes control, which is simplified by the use of composite metrics through the judgment Good, Satisfactory, Fair, and Poor. 


\section{Current Research in Diabetes \& Obesity Journal}

\section{References}

1. Rodbard D (2009) Interpretation of continuous glucose monitoring data: Glycemic variability and quality of glycemic control. Diabetes Technol Ther 11(Suppl 1): S55-S68.

2. Rodbard D (2011) Clinical interpretation of indices of quality of glycemic control and glycemic variability. Postgrad Med 123(4): 107118

3. Rodbard D (2016) Composite measures of glycemic control. Diabetes Technol Ther 18(Suppl 1): A-11-A-12. S68.

4. Kovatchev BP, Otto E, Cox D, Gonder Frederick L, Clarke W (2006) Evaluation of a new measure of blood glucose variability in diabetes. Diabetes Care 29(11): 2433-2438.

5. Hill NR, Hindmarsh PC, Stevens RJ, Stratton IM, Levy JC, et al. (2007) A method for assessing quality of control from glucose profiles. Diabet Med 24(7): 753-758.

6. Thomas A, Schönauer M, Achermann F, Schnell O, Hanefeld M, et al (2009) The Glucose Pentagon: Assessing glycemic control of patients with diabetes mellitus by a model integrating different parameters from glucose profiles. Diabetes Technol Ther 11(6): 399-409.

7. Vigerski RA (2015) Escaping the hemoglobin A1c-centric world in evaluating diabetes mellitus interventions. J Diabetes Sci Technol 9(5): 1148-1151.

8. Augstein P, Heinke P, Vogt L, Vogt R, Rackow C, et al. (2015) Q-score: development of a new metric for continuous glucose monitoring that enables stratification of antihyperglycemic therapies. BMC Endocr Disord 15: 22

9. Hirsch IB, Balo AK, Sayer K, Garcia A, Buckingham BA, et al. (2017) A simple composite metric for the assessment of glycemic status from continuous glucose monitoring data: implications for clinical practice and artificial pancreas. Diabetes Technol Ther 19(S3): S38-S48.

10. Bruttomesso D, Crazzolara D, Maran A, Costa S, Dal Pos M, et al. (2008) In type 1 diabetic patients with good glycaemic control, blood glucose variability is lower during continuous subcutaneous insulin infusion than during multiple daily injections with insulin glargine. Diabet Med 25(3): 326-332

11. Rodbard D, Baily T, Jovanovic L, Zisser H, Kaplan R, et al. (2009) Improved quality of glycemic control and reduced glycemic variability with use of continuous glucose monitoring. Diabetes Technol Ther 11(11): 717-723.

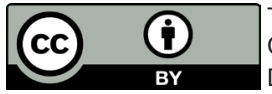

This work is licensed under Creative Commons Attribution 4.0 Licens

DOI: 10.19080/CRDOJ.2017.4.555626
12. McCall AL, Cox DJ, Brodows R, Crean J Johns D, et al. (2009) Reduced daily risk of glycemic variability: comparison of exenatide with insulin glargine. Diabetes Technol Ther 11(6): 339-344.

13. Kohnert KD, Heinke P, Vogt L, Zander E Fritzsche G, et al. (2011) Reduced glucose variability is associated with improved quality of glycemic control in patients with type 2 diabetes: a 12-month observational study. J Endocrinol Metab 1(2): 64-72.

14. Perea NV, Torres M, Cardona JA, Iniesta R (2013) Impact of telemedicine assessment on glycemic variability in children with type 1 diabetes mellitus. Diabetes Technol Ther 15(2): 136-142.

15. Perea V, Amor A, Gimenez M, Blanco J, Conget I (2013) Glycemic variability in a group of subjects with type 1 diabetes and repeated severe and non-severe hypoglycemia. J Diabetes Sci Technol 7(1): 289290.

16. Patton SR, Clements MA (2013) Average daily risk range as a measure for clinical research and routine care. J Diabetes Sci Technol 7(5): 1370-1375.

17. Kohnert KD, Augstein P, Zander E, Heinke P, Peterson K, et al. (2009) Glycemic variability correlates strongly with postprandial ß-cell dysfunction in a segment of type 2 diabetic patients using oral hypoglycemic agents. Diabetes Care 32(6): 1058-1062.

18. Van Dalem A, Demeester S, Balti EV, Decochez K, Weets I, et al. (2015) Relationship between glycaemic variability and hyperglycemic clamp-derived functional variables in (impending) type 1diabetes. Diabetologia 58(12): 2753-2764.

19.h t t p s:// n u trition j.b i o m e d c e n t ra l. c o m / articles/10.1186/1475-2891-8-22

20. Maki KC, Kelley KM, Lawless AL, Hubacher RL, Schild AL, et al. (2011) Validation of insulin sensitivity and secretion indices derived from the liquid meal tolerance test. Diabetes Technol Ther 13(6): 661-666.

21. Ahrén B, Pacini G (2004) Importance of quantifying insulin secretion in relation to insulin sensitivity to accurately assess beta cell function in clinical studies. Eur J Endocrinol 150(2): 97-104.

22. Park SA, Ko SH, Lee SH, Cho JH, Moon SD, et al. (2009) Average daily risk range-index of glycemic variability-related factor in type 2 diabetic inpatients. Korean Diabetes J 33(1): 31-39.

\begin{tabular}{|l|}
\hline \multicolumn{1}{|c|}{ Your next submission with Juniper Publishers } \\
will reach you the below assets \\
- Quality Editorial service \\
- Swift Peer Review \\
- Reprints availability \\
- E-prints Service \\
- Manuscript Podcast for convenient understanding \\
- Global attainment for your research \\
- Manuscript accessibility in different formats \\
( Pdf, E-pub, Full Text, Audio) \\
- Unceasing customer service \\
Track the below URL for one-step submission \\
https://juniperpublishers.com/online-submission.php \\
\hline
\end{tabular}

